\title{
Insulin-mediated Skeletal Muscle Vasodilation Contributes to Both Insulin Sensitivity and Responsiveness in Lean Humans
}

\author{
Alain D. Baron, ${ }^{\star *}$ Helmut O. Steinberg, ${ }^{*}$ Haitham Chaker, ${ }^{*}$ Rosalind Leaming, ${ }^{\star \ddagger}$ Ann Johnson, ${ }^{*}$ and Ginger Brechtel ${ }^{\ddagger}$ \\ ${ }^{*}$ Department of Medicine, Indiana University Medical Center, Indianapolis, Indiana 46202; and ${ }^{\ddagger}$ Richard C. Roudebush Veterans \\ Affairs Medical Center, Indianapolis, Indiana 46202
}

\begin{abstract}
Whether insulin-mediated vasodilation is important in determining insulin's overall action to stimulate glucose uptake is unknown. To this end, we measured leg glucose uptake during euglycemic hyperinsulinemic clamps performed at two insulin doses $\left(40 \mathrm{mU} / \mathrm{m}^{2}\right.$ per $\min , n=6$ and 120 $\mathrm{mU} / \mathrm{m}^{2}$ per $\min , n=15$ ) alone and during a superimposed intrafemoral artery infusion of ${ }^{\mathrm{G}} \mathrm{N}$-monomethyl-L-arginine (L-NMMA) designed to blunt insulin-mediated vasodilation. During the higher dose study, hyperinsulinema resulted in about a twofold rise in basal leg blood flow from $0.24 \pm 0.02$ to $0.45 \pm 0.05$ liter/min, $P<0.0001$. L-NMMA infusion resulted in a net $21 \%$ reduction in leg glucose uptake from $114 \pm 18 \mathrm{mg} / \mathrm{min}$ to $85 \pm 13 \mathrm{mg} / \mathrm{min}, P<0.001$. We also found a significant relationship between the rate of insulin-stimulated whole body glucose uptake and the magnitude of flow dependent glucose uptake $(r=0.57, P=0.02)$. Data obtained during the lower dose insulin infusion resulted in similar findings. In conclusion, in healthy lean subjects, insulin-stimulated muscle blood flow contributes to both insulin responsiveness and insulin sensitivity. The most insulin-sensitive subjects appear to be the most reliant on muscle perfusion for insulin action. Insulin-mediated vasodilation is an important physiological determinant of insulin action. ( $J$. Clin. Invest. 1995. 96:786-792.) Key words: glucose uptake • nitric oxide $\bullet{ }^{\mathrm{G}} \boldsymbol{N}$-monomethyl-L-arginine $\bullet$ insulin sensitivity
\end{abstract}

\section{Introduction}

Physiological insulin concentrations cause an approximate twofold increase in resting skeletal muscle blood flow in insulinsensitive but not insulin-resistant humans $(1,2)$. We have previously reported that insulin's effect to increase skeletal muscle perfusion is highly correlated with its ability to stimulate glucose uptake, suggesting a tight coupling between perfusion and insulin sensitivity (1). However, this association could only suggest but not prove a causal effect of perfusion to act as a determinant of glucose uptake.

Systemic administration of angiotensin II ( 3 ) enhances insulin-mediated glucose uptake which appears to be the result of

Address correspondence to Alain D. Baron, Indiana University Medical Center, Department of Medicine, 541 North Clinical Drive, Clinical Building 459, Indianapolis, IN 46202-5124. Phone: 317-274-1339; FAX: 317-278-0658.

Received for publication 10 August 1994 and accepted in revised form 26 April 1995.

The Journal of Clinical Investigation, Inc.

Volume 96, August 1995, 786-792 increased muscle perfusion. We have recently reported that acute increments in skeletal muscle perfusion with intraarterial methacholine which releases endothelium derived nitric oxide can markedly augment insulin stimulated leg (muscle) glucose uptake (4). These data strongly support an independent role for enhancement of muscle perfusion to modulate in vivo glucose uptake. Nevertheless, definitive evidence for the ability of insulin-mediated increments in skeletal muscle blood flow to play a role in insulin sensitivity and for reduction of perfusion to cause insulin resistance is currently lacking.

At first glance it might appear obvious that if perfusion enhancement augments glucose uptake, its reduction should lead to insulin resistance. However, reduction in blood flow $(F)$ is accompanied by increments in muscle glucose extraction (reflected by arteriovenous glucose difference, AVG $\Delta^{1}$ which can potentially offset any change in perfusion and result in no net change in glucose uptake (GU), GU $=A V G \Delta \times F(5)$. This occurs because the reduction in perfusion leads to an increase in the transit or residence time of glucose along the length of the capillary leading to greater glucose exchange. Thus, it remains to be proven and important to establish whether insulin-mediated augmentation of skeletal muscle perfusion is instrumental in determining insulin action.

We have recently reported that insulin-mediated vasodilation (perfusion) is endothelium-derived nitric oxide dependent (6) since it can be abrogated by the infusion of the specific inhibitor of nitric oxide synthase, ${ }^{\mathrm{G}} \mathrm{N}$-monomethyl-L-arginine (L-NMMA). Thus, a pharmacologic "tool" is now available to specifically reduce insulin induced vasodilation. The purpose of this study was to directly examine the role of insulin-mediated increments in skeletal muscle perfusion on insulin's action to stimulate glucose uptake. To this end, we combined the euglycemic hyperinsulinemic clamp and the leg balance technique to measure steady state rates of leg muscle glucose uptake at rest, during high physiological hyperinsulinemia and during a superimposed intrafemoral artery infusion of L-NMMA designed to blunt the insulin induced rise in muscle perfusion in a group of healthy volunteers.

\section{Methods}

Subjects. The characteristics of the study groups are shown in Table $\mathbf{I}$. 21 subjects were selected to have a body mass index of $<27$ with no family or personal history of diabetes or hypertension. All subjects were healthy and not ingesting any medications at the time of study. All were admitted to the Indiana University Clinical Research Center $2 \mathrm{~d}$ before the study and fed an isocaloric diet the caloric composition of which

1. Abbreviations used in this paper: $\mathrm{AV}$, arteriovenous; $\mathrm{AVG} \Delta, \mathrm{AV}$ glucose difference; LBF, leg blood flow; LGU, leg glucose uptake; LNMMA, ${ }^{\mathrm{G}} N$-monomethyl-L-arginine. 
Table I. Patient Characteristics*

\begin{tabular}{lcccccc}
\hline & \multicolumn{2}{c}{ Group I } & \multicolumn{2}{c}{ Group II } & \multicolumn{2}{c}{ Group III } \\
\hline & Mean \pm SEM & Range & Mean \pm SEM & Range & Mean \pm SEM & Range \\
$n$ & 6 & & 15 & & & 10 \\
Age $(\mathrm{yr})$ & $35.3 \pm 2.2$ & $26-41$ & $32.3 \pm 1.7$ & $23-46$ & $32.4 \pm 2.1$ & $26-41$ \\
Weight $(\mathrm{kg})$ & $72.0 \pm 3.6$ & $58.4-84.1$ & $66.8 \pm 2.5$ & $51.5-85.7$ & $66.9 \pm 2.7$ & $57.2-85.7$ \\
BMI $^{\ddagger}$ & $22.4 \pm 0.8$ & $19.5-24.5$ & $22.4 \pm 0.6$ & $19.3-27.3$ & $21.8 \pm 0.5$ & $19.7-24.5$ \\
Percent body fat & $17.8 \pm 2.9$ & $13.6-21.7$ & $20.1 \pm 2.1$ & $10.4-38.5$ & $16.3 \pm 1.8$ & $10.4-24.3$ \\
Fasting insulin $(\mu \mathrm{U} / \mathrm{ml})$ & $4.9 \pm 0.9$ & $1.9-7.8$ & $4.9 \pm 0.7$ & $1.3-11.8$ & $4.3 \pm 0.6$ & $1.9-7.6$ \\
Fasting glucose $(\mathrm{mg} / \mathrm{dl})$ & $94.1 \pm 2.8$ & $82.4-103$ & $92.2 \pm 1.1$ & $87-101$ & $91.2 \pm 1.0$ & $87.0-96.7$ \\
Basal map $(\mathrm{mmHg})$ & $86.1 \pm 1.6$ & $81.8-92.0$ & $82.7 \pm 1.6$ & $72.5-93.9$ & $83.5 \pm 2.2$ & $72.5-93.9$ \\
& & & & & & \\
\hline
\end{tabular}

* Data are expressed as mean \pm SEM, range of values are shown in parenthesis. Group I and II were studied at an insulin infusion rate of 40 and $120 \mathrm{mU} / \mathrm{m}^{2}$ per min, respectively. Group III is a subgroup of group II designed to match group I for body composition and other characteristics. ${ }^{\ddagger}$ BMI body mass index weight $(\mathrm{kg}) \div$ height $\left(\mathrm{m}^{2}\right)$.

was $50 \%$ carbohydrate, $30 \%$ fat, and $20 \%$ protein. All subjects were studied in the supine position after an overnight fast. Studies were conducted in a room maintained at $22^{\circ} \mathrm{C}$ and all hemodynamic measurements were performed under quiet conditions.

Protocol and analytical methods. At $\sim$ 7:00 a.m., a catheter was inserted into an antecubital vein for infusion of substances. Subsequently, both femoral vein and artery were cannulated. A 5-french sheath (Cordis Laboratories Inc., Miami, FL) was inserted in the femoral vein to allow the insertion of a custom-designed 5-Fr double-lumen thermodilution catheter (Bentley Laboratories, Irvine, CA) to measure leg blood flow (LBF) as previously described (7). The femoral artery was cannulated with a 5.5-Fr triple-lumen catheter (Arrow International, Reading, PA) to allow simultaneous infusion through the proximal port (most caudad), invasive blood pressure monitoring through the middle port, and systemic arterial blood sampling through the distal port (most cephalad). Heart rate and blood pressure were monitored via precordial leads and a pressure transducer connected to a vital signs monitor (VSM 1; Physiocontrol, Redmond, WA).

At least $30 \mathrm{~min}$ after insertion of all catheters baseline measurements of mean arterial pressure, LBF, femoral venous, and arterial concentrations of glucose and lactate were obtained. Subsequently euglycemic hyperinsulinemic clamps performed at an insulin infusion rate of 40 $\mathrm{mU} / \mathrm{m}^{2}$ per $\min$ (group I, $n=6$ ) or $120 \mathrm{mU} / \mathrm{m}^{2}$ per $\min$ (group II, $n$ $=15$ ) were carried out for at least $220 \mathrm{~min}$ to achieve steady state glucose infusion rates, femoral AVG $\Delta$, and LBF. At $\sim 240 \mathrm{~min}$, an intrafemoral artery square-wave infusion of L-NMMA (CalbiochemNovabiochem Corp., La Jolla, CA) was delivered at a rate previously established in our laboratory to achieve near complete abrogation of insulin-mediated vasodilation ( $16 \mathrm{mg} / \mathrm{min})$. The L-NMMA infusion was maintained for 30 min during which LBF was measured approximately every $35 \mathrm{~s}$ (total of $\sim 36$ determinations) and femoral AVG $\Delta$ every 2 min ( 10 determinations). Leg glucose uptake (LGU) and whole body glucose uptake were determined at baseline, during steady state euglycemic hyperinsulinemia, and during superimposed intrafemoral artery L-NMMA infusion. Steady state rates of LGU during hyperinsulinemia alone represent the mean of values obtained at 200 and $240 \mathrm{~min}$ of the clamp. Leg glucose balance was calculated as the product of the blood AVG $\Delta$ and leg blood flow. Plasma glucose was converted to blood glucose by the following formula: blood glucose = plasma glucose $\times(1-0.3 \times$ hematocrit $)$. Leg lactate balance was calculated as the product of serum lactate arteriovenous (AV) difference $\times$ plasma flow. Plasma flow $=$ blood flow $\times 1$ - hematocrit. Lactate is both taken up and produced by leg tissues, therefore the net balance is often expressed in negative values indicating net lactate release (a greater negative value indicates more lactate release from the leg).

Compared to the six subjects in group I who all exhibited a percent body fat $<22 \%$, group II (studied the higher insulin dose) exhibited a wide range of body fat content (up to $38 \%$ ). Therefore, to better compare the effect of different insulin concentrations on the metabolic and hemodynamic parameters, we compared a subgroup of subjects from group II ( $n=10$, group III) that were matched for body composition to group I (see Table I).

Analytical methods. Blood for serum glucose determinations was drawn, put in untreated polypropylene tubes, and centrifuged with an Eppendorf microcentrifuge (Brinkmann Instruments, Inc., Westbury, NY). The glucose and lactate concentrations of the supernatant were measured by the oxidase method with a glucose/lactate dual channel analyzer (model 2300 Stat; Yellow Springs Instrument Co., Yellow Springs, $\mathrm{OH}$ ). Blood for determination of plasma insulin concentrations was collected in tubes treated with heparin. The specimens were spun, and the supernatant was removed and stored at $-20^{\circ} \mathrm{C}$. Plasma insulin levels were measured by double-antibody radioimmunoassay (Coatacount; Diagnostic Products Corp., Los Angeles, CA). Blood for determination of plasma glucose-specific activity was collected in sodium fluoride-treated tubes and immediately placed on ice. The specimens were spun, and the supernatant was removed and stored at $-20^{\circ} \mathrm{C}$. At the time of assay the serum was thawed and diluted, and the proteins were precipitated with $0.6 \mathrm{M}$ perchloric acid. The supernatant was divided equally, evaporated to dryness, resuspended in $0.5 \mathrm{ml}$ distilled water to which $10 \mathrm{ml}$ of liquid scintillation counting fluid was added (National Diagnostics, Atlanta, GA), and counted for $5 \mathrm{~min}$.

Statistical analysis. Data are shown as the means \pm SE. Comparison were made using analysis of variance. Paired comparisons were performed with the one-tailed Student's $t$ test. Significance was considered at the $P<0.05$ level. All statistics were performed on a Macintosh computer with Statview IV (Abacus Concepts, Berkeley, CA).

\section{Results}

Glucose, lactate and insulin concentrations (Table II)

The mean fasting serum glucose concentration and steady state serum glucose concentration during euglycemic hyperinsulinemia ( 40 and $120 \mathrm{mU} / \mathrm{m}^{2}$ per min) with and without concomitant infusion of L-NMMA were not significantly different. Basal insulin concentrations were not different between groups. The steady state serum insulin concentration were $69 \pm 3$ and $210 \pm 13$ $\mu \mathrm{U} / \mathrm{ml}$ during euglycemic hyperinsulinemia during the 40 and $120 \mathrm{mU} / \mathrm{m}^{2}$ per min insulin infusions, respectively. During superimposed L-NMMA infusion steady state serum insulin concentrations tended on average to be higher than during insulin 
Table II. Glucose, Lactate and Insulin Concentrations

\begin{tabular}{lccc}
\hline & Basal & \multicolumn{1}{c}{ Insulin } & Insulin + L-NMMA \\
\hline Group I & & & \\
$\quad$ Plasma glucose (mg/dl) & $94.1 \pm 2.8$ & $92.6 \pm 0.8$ & $93.7 \pm 0.9$ \\
Plasma lactate (mmol/liter) & $0.76 \pm 0.10$ & $1.01 \pm 0.11$ & $1.03 \pm 0.12$ \\
$\quad$ Serum insulin $(\mu \mathrm{U} / \mathrm{ml})$ & $5.0 \pm 0.9$ & $69.3 \pm 3.0^{*}$ & $80.5 \pm 3.9^{\ddagger}$ \\
Group II & & & \\
$\quad$ Plasma glucose (mg/dl) & $92.3 \pm 1.1$ & $89.0 \pm 0.7$ & $90.1 \pm 1.0$ \\
Plasma lactate (mmol/liter) & $0.71 \pm 0.08$ & $1.30 \pm 0.09^{8}$ & $1.31 \pm 0.11$ \\
$\quad$ Serum insulin $(\mu \mathrm{U} / \mathrm{ml})$ & $4.9 \pm 0.7$ & $210.0 \pm 12.6^{*}$ & $224.0 \pm 9.8^{\|}$ \\
Group III & & & \\
$\quad$ Plasma glucose $(\mathrm{mg} / \mathrm{dl})$ & $91.2 \pm 1.0$ & $88.7 \pm 0.8$ & $91.1 \pm 1.4$ \\
$\quad$ Plasma lactate $(\mathrm{mmol} / \mathrm{liter})$ & $0.69 \pm 0.10$ & $1.37 \pm 0.13^{8}$ & $1.39 \pm 0.17$ \\
Serum insulin $(\mu \mathrm{U} / \mathrm{ml})$ & $4.3 \pm 0.6$ & $206.9 \pm 11.7^{*}$ & $224.0 \pm 10.5^{9}$ \\
& & &
\end{tabular}

${ }^{*} P<0.0001$ vs basal; ${ }^{\ddagger} P<0.01$ vs insulin alone; ${ }^{8} P<0.001$ vs basal; $" P$ $<0.0001$ group I vs group II; and $1 P=0.08$ vs insulin alone.

infusion alone. Basal- and insulin-stimulated serum arterial lactate concentrations were similar between all groups and were unchanged with L-NMMA infusion. Insulin stimulation resulted in a significant rise in arterial lactate concentrations.

\section{Rates of whole body glucose uptake}

Time course of rates of glucose uptake are shown in Fig. 1. Steady state rates of glucose uptake were $8.60 \pm 0.50$ and $11.49 \pm 0.70 \mathrm{mg} / \mathrm{kg}$ per min in groups I and II, respectively, $P$ $<0.001$. Group III exhibited a somewhat higher rate of glucose disposal than group II $(12.76 \pm 0.65 \mathrm{mg} / \mathrm{kg}$ per $\mathrm{min})$ but this was not significant, $P=$ NS (Fig. 1 ).

\section{Leg glucose and lactate balance data}

Individual data for leg glucose balance parameters at baseline, during insulin alone, and with superimposed L-NMMA are shown in Table II.

Femoral AVG $\Delta$. During steady state hyperinsulinemia the femoral AVG $\Delta$ increased 12-15-fold from baseline to $30.1 \pm 1.3,27.4 \pm 2.2$, and $29.5 \pm 2.6 \mathrm{mg} / \mathrm{dl}$ in groups I, II, and III, respectively, $P=$ NS between all groups (Table III). With superimposed intraarterial L-NMMA, the AVG $\Delta$ increased within $5 \mathrm{~min}$ of the onset of the infusion and reached a new steady state after 15 min of L-NMMA infusion (Table III and Fig. 2). The mean steady state AVG $\Delta$ during L-NMMA (15$30 \mathrm{~min}$ ) was $44.2 \pm 1.8,42.9 \pm 2.0$, and $46.2 \pm 2.3 \mathrm{mg} / \mathrm{dl}$, thus exhibiting a $48.3 \pm 8.9,66.6 \pm 11.5$, and $62.6 \pm 9.2 \%$ rise over hyperinsulinemia alone in groups I, II, and III, respectively, $P$ $=0.0001$, and $P=$ NS between groups (Fig. 2).

Basal serum lactate AV difference was $0.087 \pm 0.09$, $-0.091 \pm 0.019$, and $-0.094 \pm 0.027 \mathrm{mmol} /$ liter and increased to $-0.279 \pm 0.018,-0.288 \pm 0.018$, and $-0.298 \pm 0.023 \mathrm{mmol} /$ liter during hyperinsulinemia in groups I, II, and II, respectively, $P<0.05$ vs baseline but $P=$ NS between groups. During intraarterial L-NMMA infusion the AV difference for lactate was unchanged, $-0.272 \pm 0.034,-0.266 \pm 0.019$, and $-0.259 \pm 0.022 \mathrm{mmol} /$ liter in groups I, II, and III, respectively, $P=$ NS vs insulin alone, and $P=$ NS between groups (Table II).

Leg blood flow. Basal rates of LBF were $0.241 \pm 0.025$, $0.197 \pm 0.034$, and $0.276 \pm 0.032 \mathrm{liter} / \mathrm{min}$ and increased during steady state hyperinsulinemia to $0.404 \pm 0.055,0.455 \pm 0.046$, and $0.529 \pm 0.055 \mathrm{liter} / \mathrm{min} P<0.001$ vs baseline in all groups and $P=0.07$ group I vs group III. This represents an $\sim 100 \%$ rise above baseline in all groups, $P<0.0001$. During superim-

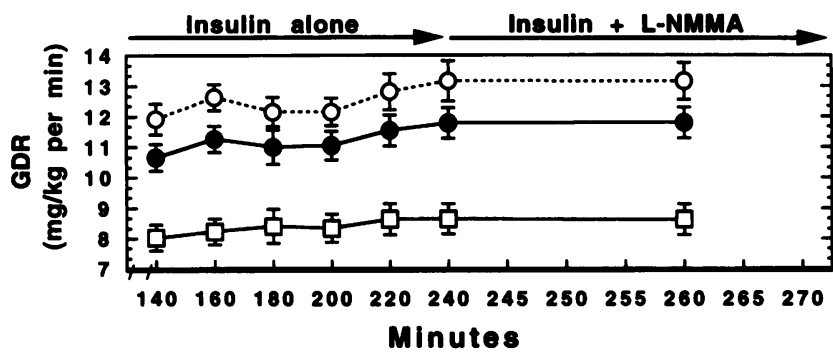

Figure 1. Rates of whole body insulin stimulated glucose disposal $(G D R)$ after 140 min of euglycemic hyperinsulinemia alone (140-240 $\mathrm{min}$ ) and after superimposed intrafemoral artery infusion of L-NMMA in six subjects studied at an insulin infusion rate of $40 \mathrm{mU} / \mathrm{m}^{2}$ per min (group I, open squares), 15 subjects studied at an insulin infusion rate of $120 \mathrm{mU} / \mathrm{m}^{2}$ per min (group II, solid circles), and a subgroup of group II (group III, open circles) matched for body composition to group I.

posed intrafemoral artery infusion of L-NMMA the rate of LBF decreased by $48.3 \pm 4.0 \%$ to $0.219 \pm 0.029 \mathrm{liter} / \mathrm{min}$ in group I, by $51.0 \pm 3.4 \%$ to $0.217 \pm 0.025 \mathrm{liter} / \mathrm{min}$ in group II, and by $54.7 \pm 3.1 \%$ to $0.205 \pm 0.029 \mathrm{liter} / \mathrm{min}$ in group III $(P<0.0001$ in all groups). The decrease in LBF was rapid and sustained occurring within 5 min of the L-NMMA infusion and remaining at this lower rate which was not different from baseline rates of leg blood flow throughout the remaining $25 \mathrm{~min}$ of L-NMMA infusion (Table III, Fig. 2).

Rates of $L G U$ and lactate balance. Hyperinsulinemia resulted in a marked rise in rates of LGU from a basal rate of $\sim 5.0 \mathrm{mg} / \mathrm{min}$ to $107.1 \pm 16.9,114.2 \pm 18.2$, and $140.4 \pm 22.9$ $\mathrm{mg} / \mathrm{min}$, in groups I, II, and III $P<0.0001$ (Fig. 3). With superimposed L-NMMA infusion steady state rates of LGU (15-30 min of L-NMMA infusion) decreased by $23.0 \pm 7.9$, $21.5 \pm 4.6$, and $28.5 \pm 3.1 \%, P<0.001$ vs baseline for all groups and $P=$ NS between groups (Fig. 3 ).

Hyperinsulinemia resulted in a marked rise in negative lactate balance (net lactate release) from a basal rate of $-0.004 \pm 0.002,-0.015 \pm 0.004$, and $-0.023 \pm 0.008$ to $-0.101 \pm 0.019,-0.094 \pm 0.015$, and $-0.143 \pm 0.022 \mathrm{mmol} / \mathrm{min}$, $P<0.0001$ vs insulin alone in groups I, II, and III, respectively. With superimposed L-NMMA infusion steady state lactate balance (15-30 min of L-NMMA infusion) decreased by $60.8 \pm 4.9 \%$ to $-0.035 \pm 0.008 \mathrm{mmol} / \mathrm{min}$ in group I, $P<0.02$, by $60.8 \pm 4.9 \%$ to $-0.035 \pm 0.008 \mathrm{mmol} / \mathrm{min}$ in group III, $P$ $<0.002$, and by $59.3 \pm 5.3 \%$ to $-0.055 \pm 0.013 \mathrm{mmol} / \mathrm{min}$ in group III, $P<0.002$.

As gauged by lactate equivalents of glucose $(2 \mathrm{~mol}$ of lactate/mol of glucose) the proportion of LGU which was released as lactate was reduced by $\sim 40 \%$ at both insulin concentrations by the L-NMMA-induced reduction of perfusion.

Correlation and other analyses. As previously reported (1) we found a significant direct relationship between the rate of leg blood flow and the rate of whole body glucose uptake during insulin stimulation, $r=0.58, P<0.01$ (Fig. 4). To explore the relationship between insulin sensitivity and the magnitude of perfusion-dependent muscle glucose uptake we examined whether a correlation exists between insulin responsiveness (rate of whole body insulin-mediated glucose uptake observed at the higher insulin dose) and the relative decrease in LGU induced by L-NMMA infusion. We found a significant inverse 
Table III. Individual Data for LBF, Femoral AVG Hyperinsulinemia (ins) with and without Superimposed Intrafemoral Artery Infusion of L-NMMA

\begin{tabular}{|c|c|c|c|c|c|c|c|c|c|}
\hline $\begin{array}{c}\text { Group II } \\
\text { Subject No. }\end{array}$ & $\begin{array}{l}\text { LBF bas } \\
\text { (liter/min) }\end{array}$ & $\begin{array}{c}\text { LBF ins } \\
\text { (liter/min) }\end{array}$ & $\begin{array}{l}\text { LBF ins + } \\
\text { L-NMMA } \\
\text { (liter/min) }\end{array}$ & $\underset{(\mathrm{mg} / \mathrm{dl})}{\operatorname{AVG} \text { bas }}$ & $\underset{(\mathrm{mg} / \mathrm{dl})}{\mathrm{AVG} \text { ins }}$ & $\begin{array}{c}\text { AVG } \Delta \text { ins }+ \\
\text { L-NMMA } \\
\text { (mg/dl) }\end{array}$ & $\begin{array}{l}\text { LGU bas } \\
\text { (mg/min) }\end{array}$ & $\begin{array}{l}\text { LGU ins } \\
\text { (mg/min) }\end{array}$ & $\begin{array}{c}\text { LGU ins + } \\
\text { L-NMMA } \\
(\mathrm{mg} / \mathrm{min})\end{array}$ \\
\hline $1 @$ & 0.205 & 0.323 & 0.233 & 1.70 & 25.3 & 35.5 & 2.97 & 70.25 & 68.05 \\
\hline $2 @$ & 0.179 & 0.283 & 0.111 & 3.10 & 9.9 & 29.4 & 4.96 & 25.23 & 29.41 \\
\hline $3 @$ & 0.145 & 0.285 & 0.201 & 2.35 & 26.4 & 41.8 & 2.95 & 66.66 & 74.49 \\
\hline $4 @$ & 0.150 & 0.236 & 0.157 & 2.50 & 32.7 & 36.6 & 3.26 & 67.91 & 50.45 \\
\hline 5 & 0.237 & 0.526 & 0.160 & 0.88 & 18.1 & 38.2 & 1.80 & 82.70 & 53.16 \\
\hline 6 & 0.187 & 0.490 & 0.215 & 2.45 & 42.0 & 53.6 & 3.93 & 117.85 & 99.68 \\
\hline 7 & 0.202 & 0.382 & 0.185 & 2.10 & 31.0 & 46.4 & 3.73 & 104.21 & 74.31 \\
\hline 8 & 0.435 & 0.761 & 0.453 & 2.55 & 44.8 & 61.8 & 9.73 & 301.24 & 247.42 \\
\hline 9 & 0.195 & 0.286 & 0.122 & 2.50 & 24.4 & 45.4 & 4.22 & 60.78 & 48.22 \\
\hline 10 & 0.210 & 0.647 & 0.338 & 0.55 & 30.2 & 40.6 & 1.01 & 171.77 & 120.64 \\
\hline $11 @$ & 0.179 & 0.409 & 0.157 & 0.43 & 22.6 & 38.2 & 0.68 & 79.58 & 51.46 \\
\hline 12 & 0.293 & 0.432 & 0.136 & 1.30 & 24.7 & 49.6 & 3.32 & 93.96 & 59.48 \\
\hline 13 & 0.191 & 0.393 & 0.232 & 1.95 & 29.2 & 41.8 & 3.16 & 98.06 & 82.83 \\
\hline 14 & 0.370 & 0.830 & 0.320 & 2.40 & 27.1 & 43.9 & 7.84 & 199.29 & 124.47 \\
\hline 15 & 0.437 & 0.542 & 0.255 & 1.15 & 23.3 & 40.4 & 4.48 & 113.78 & 92.82 \\
\hline Mean & 0.241 & $0.455^{*}$ & $0.227^{\ddagger}$ & 1.9 & $27.5 *$ & $42.9^{8}$ & 3.87 & $114.24 *$ & $85.13^{\ddagger}$ \\
\hline$\pm \mathrm{SE}$ & 0.024 & 0.046 & 0.028 & 0.2 & 2.2 & 7.9 & 0.61 & 18.21 & 13.53 \\
\hline \multicolumn{10}{|l|}{$\begin{array}{c}\text { Group I } \\
\text { Subject No. }\end{array}$} \\
\hline 1 & 0.185 & 0.452 & 0.143 & 3.8 & 32.2 & 45.6 & 6.02 & 128.95 & 59.59 \\
\hline 2 & 0.192 & 0.289 & 0.183 & 2.6 & 30.0 & 41.4 & 4.26 & 74.41 & 55.07 \\
\hline 3 & 0.149 & 0.331 & 0.210 & 2.0 & 25.8 & 49.5 & 2.57 & 74.38 & 79.76 \\
\hline 4 & 0.206 & 0.439 & 0.280 & 2.8 & 34.9 & 47.8 & 5.00 & 133.68 & 108.43 \\
\hline 5 & 0.350 & 0.636 & 0.327 & 0.7 & 30.0 & 44.0 & 1.95 & 166.19 & 124.94 \\
\hline 6 & 0.102 & 0.276 & 0.173 & 2.6 & 27.5 & 37.1 & 2.25 & 65.56 & 50.72 \\
\hline Mean & 0.197 & $0.404^{\prime \prime}$ & $0.219^{\ddagger}$ & 2.4 & $30.1^{11}$ & $44.2^{\ddagger}$ & 3.67 & $107.14^{\|}$ & $79.75^{1}$ \\
\hline$\pm \mathrm{SE}$ & 0.034 & 0.055 & 0.029 & 0.43 & 1.36 & 1.8 & 0.68 & 16.90 & 12.55 \\
\hline
\end{tabular}

Subjects in Group I and II were studied at an insulin infusion rate of $40-120 \mathrm{mU} / \mathrm{m}^{2}$ per min, respectively. ${ }^{*} P<0.0001$ vs baseline; ${ }^{\ddagger} P<0.001$ vs insulin alone; $P<0.0001$ vs insulin alone; " $P<0.001$ vs baseline; and $1 P<0.05$ vs insulin alone. @ subjects not included in group III based on percent body fat $>24.4$.

relationship between the degree of insulin responsiveness (insulin-mediated whole body glucose uptake) and the proportion of flow dependent glucose uptake, $r=0.57, P=0.02$, respectively (Fig. 5). Thus, those subjects who were most insulin responsive tended to have both the greatest flow increments and conversely the greatest degree of flow dependent glucose uptake.

There was no relationship between the rate of insulin-mediated blood flow and arterial or venous lactate concentration or lactate AV differences at either insulin concentration. Likewise, there was no relationship between the AVG $\Delta$ and the rate of whole body glucose uptake across all groups.

\section{Discussion}

We $(1,2)$ and others $(8,9)$ have previously demonstrated that insulin vasodilates skeletal muscle vasculature over physiological concentrations in normal humans. Moreover, we have also shown a strong correlation between the degree of insulin sensitivity and the ability of insulin to increase skeletal muscle blood flow (1). These data suggested but did not provide proof that these two physiological events were causally related. The cur- rent study is the first time demonstration that insulin-mediated vasodilation plays a significant role in the determination of both insulin sensitivity and responsiveness as measured during a euglycemic hyperinsulinemic clamp in lean subjects.

In the current study we elected to first stimulate skeletal muscle blood flow and glucose uptake with steady state insulin concentrations in the physiologic $(\sim 75 \mu \mathrm{U} / \mathrm{ml})$ and high but subpharmacologic range $(\sim 200 \mu \mathrm{U} / \mathrm{ml})$. This resulted in an approximate twofold increase in leg blood flow above baseline at both insulin concentrations consistent with our previous reports $(1,2,9)$. After reaching steady state rates of glucose uptake and leg blood flow, we performed an intrafemoral artery infusion of L-NMMA designed to abolish the insulin-mediated rise in leg blood flow. With this maneuver we were able to completely reverse the insulin-mediated vasodilation and thus, reestablish basal rates of leg blood flow as we have recently reported (6). Therefore, we established an experimental condition where insulin action was fully expressed but where the normal rise in skeletal muscle perfusion was restrained and leg blood flow was maintained at basal rates for sufficient time to establish steady state conditions. Despite a $\sim 50 \%$ increase in 

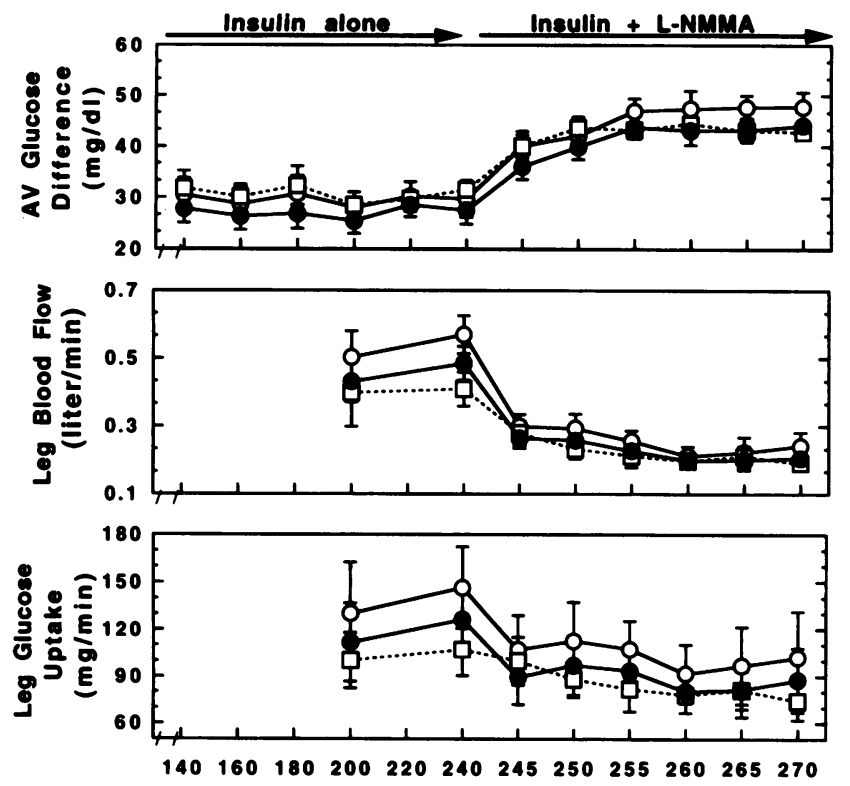

Minutes

Figure 2. Femoral AV glucose differences (top), rates of leg blood flow (middle) and rates of leg glucose uptake (bottom) under steady state conditions after $200 \mathrm{~min}$ of euglycemic hyperinsulinemia and at 5-min intervals during a 30-min intrafemoral artery infusion of $\mathrm{L}$ NMMA designed to reduce leg skeletal muscle blood flow in six subjects studied at an insulin infusion rate of $40 \mathrm{mU} / \mathrm{m}^{2}$ per min (group I, open squares), 15 subjects studied at an insulin infusion rate of $120 \mathrm{mU} / \mathrm{m}^{2}$ per min (group II, solid circles), and a subgroup of group II (group III, open circles) matched for body composition to group I.

the AVG $\Delta$, we observed an average $\sim 20-30 \%$ reduction in rates of LGU in body composition-matched subjects studied at both the lower and higher insulin infusion rates (Fig. 3). Moreover, it is noteworthy that while subjects studied at the lower insulin dose (group I) displayed rates of whole body glucose uptake that were 33\% lower than their lean counterparts studied at the higher insulin dose (group III), the femoral AVG $\Delta$ was similar in the two groups. Given that the rate of leg blood flow was higher in group III than in group I, one also can infer that the rate of muscle perfusion is an important determinant of the overall rate of glucose uptake. Thus, one can conclude that in healthy lean men, $\sim 20-30 \%$ of the overall rate of insulin-mediated glucose uptake is dependent on incre-

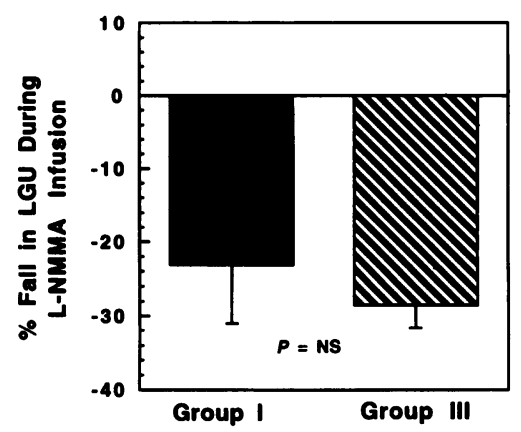

Figure 3. Percent reduction in rates of leg glucose uptake during superimposed intrafemoral artery infusion of LNMMA (255-270 min) in six subjects studied at an insulin infusion rate of $40 \mathrm{mU} / \mathrm{m}^{2}$ per $\min$ (group I, solid bar) and 10 body compositionmatched subjects studied at an insulin infusion rate of $120 \mathrm{mU} / \mathrm{m}^{2}$ per $\min$ (group III, hatched bar).

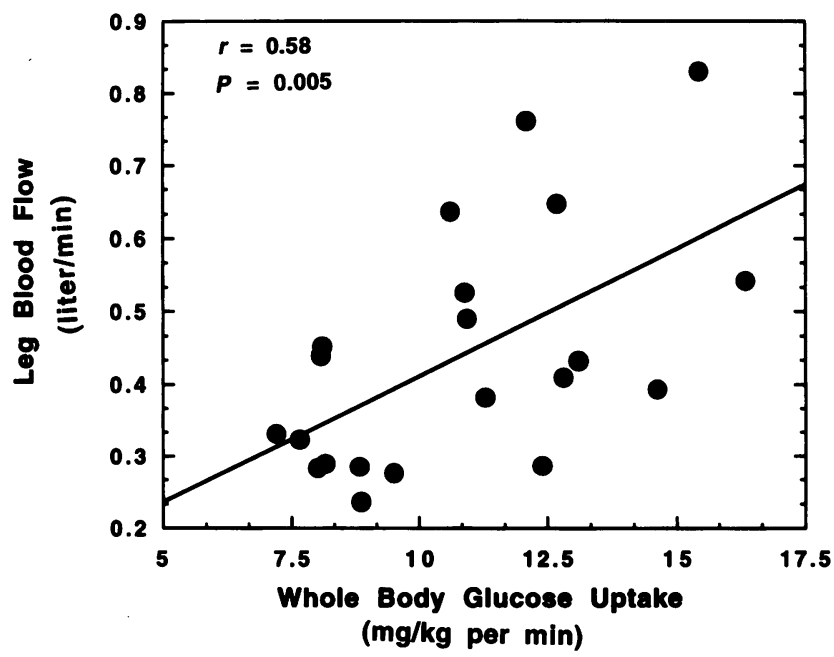

Figure 4. Correlation between insulin mediated glucose disposal (GDR) and rates of leg blood flow during steady state euglycemic hyperinsulinemia in subjects studied at an insulin infusion rate of $120 \mathrm{mU} / \mathrm{m}^{2}$ per $\min$ (group II, $n=15$ ) and $40 \mathrm{mU} / \mathrm{m}^{2}$ per $\min$ (group I, $n=6$ ).

ments in muscle perfusion at both submaximally effective (insulin sensitivity), and near maximally effective insulin concentrations (insulin responsiveness).

Closer inspection of the data reveals wide individual variation in the degree of perfusion-dependent LGU. In this regard, it is important to keep in mind that the rate of leg blood flow is directly related to the rate of glucose uptake (Fig. 4). Therefore, if the rise in muscle perfusion is a determinant of the rate of insulin-stimulated glucose uptake one would expect that those individuals who exhibit the greatest insulin responsiveness (and

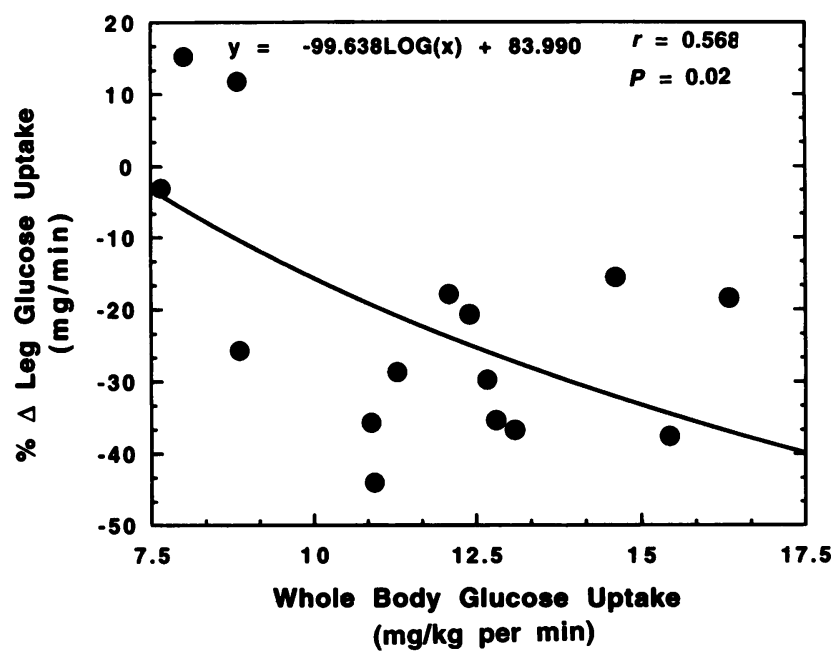

Figure 5. Correlation between the degree of insulin responsiveness as gauged by the rate of whole body insulin-mediated glucose disposal measured at an insulin infusion rate of $120 \mathrm{mU} / \mathrm{m}^{2}$ per min (group II, $n=15$ ) and the relative change in leg glucose uptake in response to L-NMMA-induced reduction of leg blood flow. A log fit was utilized as it best represented the data. Linear regression yielded an $r=0.546$, $P=0.04 ;$ a second degree polynomial fit yielded an $r=0.743, P$ $=0.01$. 
also the highest rates of leg blood flow) would also display the greatest diminution of LGU in response to L-NMMA. The significant inverse relationship between the rate of insulin-mediated glucose uptake and the fall in LGU in response to LNMMA suggests that this is indeed the case (Fig. 5). It is noteworthy that 3 of the 21 subjects studied (No. 3 in group I and No. 2 and 3 in group II) appear to have had modest (7$15 \%$ ) increases in LGU in response to L-NMMA in the face of a reduction in leg blood flow. While it is possible that this represents an actual increase in LGU, it is more likely that this simply reflects the error in the methodology. The AVG $\Delta$ is a very robust number only subject to the error of the glucose analyzer (1-2\%); in contrast, the measurement of limb blood flow is more variable both for biological and technical reasons (the overall coefficient of variation is probably closer to $15 \%$ ). Our technique to measure blood flow, while highly sensitive and accurate, is not devoid of error. Therefore, it is likely that due to error in the flow measurement the rise in LGU in these subjects is more apparent than real and that the actual change in LGU is closer to zero. Likewise, it is equally likely that we overestimated, to a similar degree, the fall in LGU in response to L-NMMA. If one considers the balance equation (LGU $=$ AVG $\Delta *$ flow) it is easy to see how a small change (or error) in one of the parameters of the equation can have a large impact on the balance value. Despite this inherent methodological difficulty, we have found highly significant $(P<0.001)$ overall reductions in LGU when leg blood flow was reduced with L-NMMA, lending further strength to our observations.

The current data do not address the role of perfusion in determining tissue insulin sensitivity in classic states of insulin resistance such as obesity and non-insulin-dependent diabetes mellitus (NIDDM). Simple theoretical models for glucose exchange across capillary membranes as proposed by Renkin (10) predict that individuals who exhibit the greatest degree of tissue permeability to glucose would be expected to display the greatest amount of flow-dependent uptake. Compared to lean insulin sensitive subjects, obese and NIDDM patients exhibit smaller AVG $\Delta$ s during insulin stimulation despite the fact that in these subjects muscle perfusion is modest which would tend to increase the AVG $\Delta(1,2,11)$. This suggests that glucose permeability is very poor and thus, one would not expect that an augmentation of muscle perfusion would have much modulating effect on glucose uptake in these subjects. Weight reduction and glycemic control greatly ameliorate (but do not normalize) insulin action in obese subjects by virtue of an increase in glucose extraction (12). The persistent impairment in the hemodynamic response to insulin, however, could potentially contribute to the inability to normalize glucose uptake in these subjects. Clearly, more direct experimental data are required to determine the actual contribution of impaired tissue perfusion to insulin action in insulin resistant subjects.

We have previously proposed (13) that insulin-mediated vasodilation may augment glucose uptake via a mechanism of capillary recruitment. This theoretical proposal holds that via the release of endothelium-derived nitric oxide insulin first vasodilates the precapillary arteriole thus, increasing flow to muscle. Via this increased perfusion, muscle capillaries are then recruited, resulting at any point in time in a greater number of perfused capillaries (increased functional capillary density) with increased delivery of glucose and insulin. In the current study design (group II) insulin action was near maximal and in steady state, suggesting that the tissues were fully insulinized, therefore it is not likely that interstitial insulin levels were altered over the $30-\mathrm{min}$ period of perfusion reduction. Thus, it is all the more remarkable that an acute reduction of perfusion lead to such marked decreases in glucose uptake and metabolism (as evidenced by the reduction in net lactate release). A more likely explanation for the decrement in glucose uptake is that the reduction in muscle perfusion induced by L-NMMA resulted in capillary derecruitment and an accompanying fall in glucose delivery.

The current data may have an important impact upon our current understanding of insulin resistance. It is possible, for example, that certain forms of insulin resistance are either entirely or in part secondary to defective insulin-mediated vasodilation. We have previously proposed that the insulin resistance associated with essential hypertension could be accounted for by a failure of insulin-mediated vasodilation (14) and recent data from our laboratory support this idea. We have reported that acute systemic infusion of L-NMMA in rats which results in both elevated blood pressure and decreased skeletal muscle perfusion (15) is associated with a marked reduction in rates of insulin-mediated glucose uptake (16). Moreover, we have recently reported that in humans insulin-mediated vasodilation is inversely related to the height of the resting blood pressure (14).

Finally, the results of our study are in part based upon the assumption that L-NMMA has no effect to reduce cellular glucose permeability per se. We have recently tested this idea by examining the effect of L-NMMA upon insulin stimulation of $\left[{ }^{14} \mathrm{C}\right]$ glucose incorporation into glycogen in isolated rat soleus muscle (16). The data indicate that L-NMMA does not appear to have any effects on overall cellular membrane glucose transport and glycogen formation. While the effects of L-NMMA on insulin action are likely to be secondary to its hemodynamic action, one cannot completely rule out a direct effect of $\mathrm{L}$ NMMA on cellular glucose uptake in vivo.

In conclusion, the current data support the notion that in lean individuals, insulin's action to increase skeletal muscle perfusion can account for as much as one-third of insulin's overall effect to stimulate glucose uptake. Therefore, it follows logically that a defect in this hemodynamic action could result in insulin resistance. Thus, the cardiovascular actions of insulin appear to be an integral part of insulin's overall effect to increase glucose disposal. Finally, it is possible that insulin substrates other than glucose (amino acids and lipids) are similarly modulated.

\section{Acknowledgments}

The authors which to thank Shirley Kendrick for her expert and invaluable help in preparing the manuscript.

This work was supported in part by grants DK42469, MO1-RR75019, and DK20542 from the National Institutes of Health, a Veterans Affairs Merit Review Award, and a grant-in-aid from the American Heart Association.

\section{References}

1. Laakso, M., S. V. Edelman, G. Brechtel, and A. D. Baron. 1990. Decreased effect of insulin to stimulate skeletal muscle blood flow in obese man: a novel mechanism for insulin resistance. J. Clin. Invest. 85:1844-1852.

2. Laakso, M., S. V. Edelman, G. Brechtel, and A. D. Baron. 1992. Impaired 
insulin mediated skeletal muscle blood flow in patients with NIDDM. Diabetes. 41:1076-1083.

3. Buchanan, T. A., H. Thawani, W. Kades, J. G. Modrall, F. A. Weaver, C Laurel, R. Poppili, A. Xiang, and W. Hsueh. 1993. Angiotensin II increases glucose utilization during acute hyperinsulinemia via a hemodynamic mechanism. J. Clin. Invest. 92:720-726.

4. Baron, A. D., H. Steinberg, G. Brechtel, and A. Johnson. 1994. Skeletal muscle blood flow independently modulates insulin-mediated glucose uptake. Am. J. Physiol. 266:E248-E253.

5. Zierier, K. L. 1961. Theory of the use of arteriovenous concentration differences for measuring metabolism in steady and non-steady state. J. Clin. Invest. 40:2111-2125.

6. Steinberg, H. O., G. Brechtel, A. Johnson, and A. D. Baron. 1993. Insulin modulates endothelium derived relaxing factor/nitric oxide dependent vasodilation in skeletal muscle. Hypertension (Dallas). 22:P74-436.

7. Baron, A. D., G. Brechtel, P. Wallace, and S. V. Edelman. 1988. Rates and tissue sites of non-insulin and insulin mediated glucose uptake in humans. Am. J. Physiol. 255:E769-E774.

8. Anderson, E. A., R. P. Hoffman, T. W. Balon, C. A. Sinkey, and A. L Mark. 1991. Hyperinsulinemia produces both sympathetic neural activation and vasodilation in normal humans. J. Clin. Invest. 87:2246-2252.

9. Vollenweider, P., L. Tappy, D. Randin, E. Jequier, P. Nicod, and R. Scherrer. 1992. Hyperinsulinemia, not carbohydrate oxidation is the primary stimulus for both sympathetic activation and vasodilation in humans. Diabetes. 41:66a. (abstr.)

10. Renkin, E. M. 1979. Control of microcirculation and blood-tissue exchange. In Handbook of Physiology: The Cardiovascular System IV. R. M. Berne N. Sperelakis, and S. E. Geiger, editors. Williams \& Wilkins, Baltimore, MD 627-687.

11. Castillo, C., C. Bogardus, R. Bergman, P. Thuillex, and S. Lillioja. 1994 Interstitial insulin concentrations determine glucose uptake rates but not insulin resistance in lean and obese man. J. Clin. Invest. 93:10-16.

12. Baron, A. D., M. Laakso, G. Brechtel, and S. V. Edelman. 1991. Reduced capacity and affinity of skeletal muscle for insulin mediated glucose uptake in non-insulin dependent diabetic subjects. Effects of insulin therapy. J. Clin. Invest. 87:1186-1194.

13. Baron, A. D. 1994. Hemodynamic actions of insulin. Am. J. Physiol. 267:E187-E202.

14. Baron, A. D., G. Brechtel-Hook, A. Johnson, and D. Hardin. 1993. Skeletal muscle blood flow. A possible link between insulin resistance and blood pressure. Hypertension (Dallas). 21:129-135.

15. Loeb, A. L., and D. E. Longnecker. 1992. Inhibition of endothelium derived relaxing factor dependent circulatory control in intact rats. Am. J. Physiol. 262:H1494-H1500.

16. Keech, C., J.-S. Zhu, G. Brechtel, and A. D. Baron. 1995. Acute hypertension induced by L-NMMA causes insulin resistance in rats. Am. J. Physiol. In press. 